\title{
Oportunidades de letramento através de mineração textual e produção de Fanfictions
}

\section{Opportunities of literacy through text mining and Fanfiction writing}

Patrícia da Silva Campelo Costa*

Universidade Federal do Rio Grande do Sul

Porto Alegre - Rio Grande do Sul / Brasil

Eliseo Berni Reategui**

Universidade Federal do Rio Grande do Sul

Porto Alegre - Rio Grande do Sul / Brasil

RESUMO: Este trabalho tem por objetivo investigar como o letramento pode ser apoiado pelo uso de um recurso digital passível de auxiliar os processos de leitura e produção textual. Assim, a presente pesquisa baseia-se nos estudos de Feldman e Sanger (2006) acerca da mineração de textos e nas pesquisas de Black (2007; 2009) sobre a incorporação de um gênero textual característico da internet (fanfiction) na aprendizagem de línguas. Através da utilização de um recurso de mineração de texto (Sobek), a partir do qual ocorre a extração dos termos mais recorrentes em um texto, os participantes deste estudo criaram narrativas em inglês como língua estrangeira (LE), em meio digital. Observou-se que a utilização da ferramenta deu suporte à produção textual em LE, e sua subsequente prática de letramento, visto que os alunos se apoiaram no recurso de mineração para criar narrativas fanfiction.

PALAVRAS-CHAVE: letramento, fanfiction, mineração de texto.

ABSTRACT: This work aims at investigating how literacy may be supported by the use of a digital resource which can help the process of reading and writing. Thus, the present work is based on studies by Feldman and Sanger (2006) about text mining, and on research by Black $(2007 ; 2009)$ about the incorporation of a textual genre characteristic of the Internet (fanfiction) in language learning. Through the use of a text mining resource (Sobek), which promotes the extraction of frequent terms present in a text, the participants of our pilot study created

patricia.campelo@yahoo.com.br

**eliseoreategui@gmail.com 
narratives in English as a foreign language (FL), in digital media, and used the mining tool to develop graphs with the recurrent terms found in the story. It was observed that the use of a digital tool supported the text production in the FL, and its following practice of literacy, as the students relied on the mining resource to create their fanfictions.

KEYWORDS: literacy, fanfiction, text mining.

\section{Introdução}

Ferramentas digitais que podem ser eficazes no processo de desenvolvimento do letramento em língua estrangeira (LE) têm a possibilidade de atuar como recursos mediadores para tarefas pedagógicas. Em relação a esse campo de confluência, vários estudiosos estabeleceram relações entre a tecnologia, a linguagem e o letramento (KERN; WARSCHAUER, 2000; 2001; LANKSHEAR; KNOBEL, 2007). Dessa maneira, é importante que os professores atuantes nessas áreas convergentes façam uso de recursos eletrônicos de modo significativo, a fim de criar tarefas que possam englobar processos de letramento no aprendizado de LE. Na presente pesquisa, o letramento é considerado um processo através do qual a aprendizagem de línguas pode ocorrer baseada no desenvolvimento de práticas de leitura e escrita socialmente significativas (BARTON; HAMILTON, 2000). Tendo como ponto de partida a leitura e a análise do gênero textual fanfiction (história publicada na internet, produzida por fãs de símbolos da mídia, representados por filmes e seriados, por exemplo), o processo de letramento em uma LE é examinado, o qual pode se desenvolver através da relação entre a tecnologia e a aprendizagem de línguas.

Assim, este trabalho investiga como uma ferramenta de mineração de texto pode auxiliar na produção de textos em inglês como língua estrangeira por alunos de graduação no Brasil. Tal ferramenta opera fazendo a identificação automática de termos relevantes e seus relacionamentos em um texto. Dessa maneira, observa-se como o ambiente digital pode ser um instrumento de apoio ao processo de aprendizagem através de uma tarefa na qual a ferramenta de mineração de texto é mediadora da produção escrita. Para tanto, foi investigado como alunos de língua estrangeira lidam com o processo de criação de narrativas fanfiction, usando a ferramenta de mineração. Observou-se, então, como o dispositivo digital de mineração pode sustentar a produção desse texto, caracterizado por ser um gênero textual típico da web.

Numerosos estudos têm enfatizado o uso de ferramentas digitais no processo de aprendizagem de línguas estrangeiras (WIBLE; KUO; TSAO, 
2004). Uma questão que ainda necessita ser pesquisada, no entanto, é em que medida certas ferramentas, tal como o dispositivo proposto neste estudo, podem auxiliar no processo de letramento, de modo que gêneros textuais autênticos do meio on-line (neste caso, fanfiction) possam ser produzidos. Assim, neste trabalho o processo de letramento em língua estrangeira decorre dos estágios de leitura e escrita através dos seguintes meios: a) o envolvimento do aprendiz em uma tarefa pedagógica a partir da criação de um gênero textual tipicamente on-line; b) apoio à produção escrita através do uso de uma ferramenta de mineração que pode amparar o aluno na criação de um novo texto e a qual pode desencadear produção autêntica.

Para os fins desta pesquisa, a leitura é promovida através do contato com websites sobre fanfictions, em uma fase anterior àquela na qual os alunos examinam esses textos como modelos para a criação de novas narrativas. Ao analisar as fanfictions, os alunos são capazes de usar um dispositivo de mineração que pode ajudar o leitor a identificar padróes linguísticos recorrentes em fanfictions. Dessa maneira, os alunos terão realizado um exame da estrutura textual antes de iniciar a criação de um novo texto.

Ao produzir o gênero textual enfatizado neste trabalho, os autores/fãs baseiam suas criações em histórias pré-existentes, enquanto modificam e acrescentam elementos à sinopse original, incluindo, por exemplo, novas relações entre os personagens (BLACK, 2007). Assim, espera-se explorar o processo de letramento em LE por meio de observação da leitura e escrita de fanfictions por estudantes que possam encarar essa prática como um momento de produção textual significativa.

\section{Letramento e tecnologia}

Pode-se observar que alguns pesquisadores brasileiros já se preocupam em aliar as noções de letramento e o uso de tecnologias (BUZATO, 2001; SOARES, 2002; BUZATO, 2007), abarcando, desse modo, o foco em novos letramentos. Assim, esta pesquisa agrega a área de tecnologia educacional aos estudos em Linguística Aplicada, buscando criar interfaces multidisciplinares entre esses domínios.

Quanto à literacia, ${ }^{1}$ é possível observar que ocorrem processos de novos letramentos quando novos gêneros textuais são introduzidos na vida corrente

${ }^{1}$ No presente estudo, os termos letramento e literacia são utilizados de modo intercambiável. 
em sociedade. Por sua vez, letramento não envolve apenas leitura e escrita, visto que é considerado um processo significativo de prática social do indivíduo, a partir do qual ele pode atuar em contextos interacionais de produção (LANKSHEAR; KNOBEL, 2007). De acordo com Sylvia Scribner e Michael Cole (1981), a prática social se refere a modos socialmente desenvolvidos e padronizados de usar tecnologia e conhecimento na execução de tarefas. Desse modo, o letramento envolveria a aplicação de habilidades tais como a leitura e a escrita em contextos específicos de uso para propósitos específicos. Similarmente, para Brian V. Street (2001), práticas de letramento seriam modos específicos de ler, escrever e refletir sobre esses processos em contextos de uso específicos. Nessa mesma linha, conforme James Gee, Glynda Hull e Colin Lankshear (1996), para ler e escrever textos específicos, é necessária uma imersão nas práticas sociais em que participantes não apenas leem, mas também portam certas atitudes e valores em relação a essas produçóes, de modo a interagir socialmente com e a partir desses textos. Seria, assim, impossível descontextualizar a noção de letramento das práticas sociais inerentes a essa experiência.

Para Leda V. Tfouni (1995, p. 20), "o letramento focaliza os aspectos sócio-históricos da aquisição de um sistema escrito por uma sociedade". No entanto, além desse sistema escrito, observamos que os novos letramentos são permeados por material on-line a partir do qual o leitor se utiliza de outros conhecimentos que não se limitam à leitura tradicional em papel. Conforme Magda Soares (2002, p. 146), há "novas e incipientes modalidades de práticas sociais de leitura e de escrita, propiciadas pelas recentes tecnologias de comunicação eletrônica”. Os usuários da rede estão constantemente interagindo através de programas de mensagens instantâneas, criando e postando material midiático, escrevendo e comentando em blogs, por exemplo.

Desse modo, partimos para uma perspectiva sociocultural de letramento, visto que sob esse viés os processos de leitura e escrita somente podem ser compreendidos nos contextos de prática social, cultural, política e histórica dos quais fazem parte (LANKSHEAR; KNOBEL, 2007). Assim, para este trabalho seguimos o conceito de Soares, segundo o qual letramento é

o estado ou condição de quem exerce as práticas sociais de leitura e de escrita, de quem participa de eventos em que a escrita é parte integrante da interação entre pessoas e do processo de interpretação dessa interação (SOARES, 2002, p. 145). 
A noção de letramento em LE deste trabalho também se relaciona à ideia de letramento digital, a partir da qual os usuários do ambiente midiático fazem uso social de sua construção de conhecimento, a partir de meios digitais. Conforme Mark Warschauer (2006), é essencial que recursos físicos, digitais, humanos e sociais sejam levados em conta, de modo a compor um sistema funcional de partilha de conhecimentos. Em relação ao letramento digital, o mesmo autor o caracteriza como um processo no qual o usuário, além de ter conexão à internet, tem "habilidades e entendimento para utilizar o computador e a internet de modo socialmente válido" (WARSCHAUER, 2006, p. 55). Desse modo, observamos a importância de um processo de aprendizagem baseado no letramento em língua que abarque também uma preocupação com as potencialidades do letramento digital.

\section{Os novos letramentos}

Gee (1996), assim como Glynda Hull e Katherine Schultz (2001), propõem um estudo dos novos letramentos baseado na teoria sociocultural, de maneira que haja um foco na relação entre prática social, produção, troca e construção de sentido. Exemplos típicos de práticas de novos letramentos seriam os video games, a escrita de fanfictions, a produção de blogs e práticas sociais relacionadas ao uso de tecnologia móvel $^{2}$ (LANKSHEAR; KNOBEL, 2007). Em geral, os novos letramentos envolvem práticas que tendem a ser mais desenvolvidas em contextos extraescolares. Assim, a proposta deste trabalho pretende justamente fomentar a incorporação de tais experiências de literacia às práticas escolares de aprendizagem em LE. Com essa meta, um importante questionamento de Joanna C. Street e Brian V. Street (1991) vem, então, à tona: se há tantas práticas de letramento diferenciadas, por que o letramento escolar se restringe aos procedimentos tradicionais de leitura e escrita? Dessa maneira, a presente pesquisa aspira justamente identificar como um desses novos processos de letramento pode ser contemplado em tarefas propostas em LE.

Os estudos em novos letramentos (GEE, 1996; STREET, 1995; LANKSHEAR; KNOBEL, 2003) estão embasados na teoria sociocultural de letramento, a partir da qual todas as formas de literacia se emolduram a partir

\footnotetext{
${ }^{2}$ A tecnologia móvel refere-se, por exemplo, ao uso de celulares, redes sem fio, computadores portáteis etc.
} 
do contexto social, cultural e histórico (STONE, 2007). Por essa razão, os estudos de novos letramentos se dedicam cada vez mais às formas digitais de comunicação, visto que esse terreno virtual tende a adentrar os mais diversos contextos nos quais há uso da linguagem. De acordo com Stone (2007), ao reconhecer a importância e o valor de práticas de letramentos em comunidades on-line extraescolar, o educador pode explorar essas novas experiências como fontes de aprendizado, inclusive para letramentos previstos em aula.

Uma abordagem sociocultural de letramento inclui, portanto, os processos de leitura, escrita e construção de significado como elementos da prática social (LANKSHEAR; KNOBEL, 2007). Quanto aos estudos socioculturais, Lev S. Vygotsky (1986) considerava a linguagem como ferramenta psicológica central, visto que essa teria uma grande influência em nosso pensar e interagir no mundo. Desse modo, tal ferramenta seria responsável por estruturar nossa atividade mental, mediando pensamento, ação e interação. De acordo com Hull e Schultz (2001), no pensamento vygotskiano, um dos aspectos fundamentais do letramento - a escrita - seria uma ferramenta de mediação, visto que a linguagem textual escrita poderia atuar como um instrumento para o pensamento. Em relação à mediação, fundamentando-se nos estudos de Vygotsky (1998), Marília dos S. Lima e Patrícia da S. Campelo Costa (2010) defendem que esse seria o processo decorrente das tarefas colaborativas, e os processos de interação e mediação trariam benefício ao indivíduo, por permitirem o prosseguimento de uma tarefa, a qual talvez não fosse realizada sem esse auxílio.

Desse modo, temos as noções de linguagem como mediação, mediação entre indivíduos e ferramentas de mediação, que no suporte digital ultrapassam apenas a escrita. Além disso, os mecanismos de produção e difusão da escrita também são alterados no meio digital, visto que diversos autores têm oportunidade de publicar seus materiais em um ambiente no qual a interferência do leitor é muito forte. Na criação de blogs, por exemplo, o feedback do leitor é essencial para que a postagem de novos textos na página seja mantida. Por sua vez, a elaboração de fanfictions costuma ocorrer em capítulos, a fim de que a continuidade dos textos esteja vinculada à resposta oferecida pelos leitores (BLACK, 2007). Desse modo, ocorrem transformações profundas nas relaçôes entre autor e leitor, as quais, frequentemente, fundemse de maneira a imbricar os papéis de quem é produtor na rede.

De acordo com Lankshear e Knobel (2007), essas novas práticas de letramento focalizariam o compartilhamento de conhecimentos (e não a sua 
centralização), a inteligência coletiva e a colaboração. A inteligência coletiva é um efeito do pensamento e da negociação conjunta que emergem na cibercultura (LÉVY, 1998), a qual Soares (2002) chama de cultura da tela em contrapartida à cultura do papel. Tal processo de focalização no aspecto colaborativo parece ter emergido na passagem da web 1.0 para a web 2.0. A web 1.0 foi a "fase em que usuários navegavam na internet com o intuito único e exclusivo de procurar informação. Era basicamente uma experiência unilateral, semelhante à ida a uma biblioteca para procurar um livro" (PINHEIRO, 2011, p. 67). Assim, a primeira fase da web focalizava o uso, a recepção e o consumo. Diferentemente, a web 2.0 - conforme expressão cunhada por O’Reilly (2005) - teria como meta a produção e o compartilhamento colaborativo, de modo que nessa fase as práticas de novos letramentos se inserem. De tal modo, a web 2.0 tornou-se um espaço no qual qualquer indivíduo pode publicar, sem que haja trâmites editorais de impedimento. Haveria, então, "uma arquitetura de participação" (PINHEIRO, 2011, p. 67), apontando a passagem da broadcast media (a mídia com foco na transmissão) para a networked media (a mídia das redes não centralizadas).

Conforme a noção de práticas de letramento, a aprendizagem de LE, então, se daria como prática social, de modo a requerer do aprendiz participação intensa de maneira colaborativa, a fim de compartilhar seu processo de aprendizado com os colegas. No trabalho aqui proposto focalizamos o letramento sob o ponto de vista da leitura e produção textual através da utilização de ferramentas digitais e, a partir desse conceito, busca-se proporcionar aos alunos uma maior participação nas redes complexas disponíveis pelo ambiente digital. Visto que o letramento pode ser definido como um "estado ou condição de quem não só sabe ler e escrever, mas exerce as práticas sociais de leitura e escrita que circulam na sociedade em que vive, conjugando-as com as práticas sociais de interação oral" (SOARES, 1999), propõe-se um trabalho no qual o compartilhamento das produçóes textuais, através da escrita e publicação on-line, está relacionado ao caráter colaborativo, participativo e inacabado do processo de escrever em ambiente digital. Com a utilização da ferramenta de mineração espera-se estabelecer um ciclo no qual os alunos promovam construçôes colaborativas, a fim de gerar uma prática social que pode se constituir em letramento na LE, em ambiente digital.

Como afirmado no início desta seção, algumas práticas de letramento digital parecem ser, muitas vezes, recorrentes ao contexto extraescolar do aprendiz, tais como a postagem em blogs, a criação de fanfictions, as postagens 
em fóruns de discussão relacionados às preferências dos alunos etc. No entanto, essas práticas de literacia, que podem abarcar ensejos de aprendizagem mais significativa ao aluno, são, às vezes, ignoradas em sala de aula - mesmo em contextos de ensino a distância (EAD) mediado por computador. A partir dessa reflexão, Hull e Schultz (2001) propõem em seu trabalho um interessante questionamento: como os professores devem incorporar no contexto escolar os interesses e preferências dos alunos de modo que seu domínio de letramento seja ampliado? Talvez a inclusão de tarefas focalizadas em hipertextos multimodais diminua a distância entre as prioridades dos aprendizes e a literacia proposta em sala de aula, de modo a possibilitar a inserção de práticas sociais comuns do ambiente digital no meio educacional. De tal modo, o professor tem também a oportunidade de refletir como se dá o processo de letramento quando novas tecnologias são incorporadas no contexto escolar, de maneira a elaborar tarefas que fomentem práticas de literacia. Tais tarefas podem incluir gêneros textuais habitualmente não contemplados em sala, para que o aprendiz seja um indivíduo multiletrado na era da informação. Assim, a próxima seção tem como foco o gênero fanfiction, o qual se insere como prática recorrente nas novas literacias desenvolvidas na rede.

\section{O gênero textual fanfiction}

De acordo com John Swales (1990), os gêneros são advindos de uma necessidade de sua comunidade discursiva, de modo que esses textos reflitam os valores da comunidade em que são produzidos. Assim, o gênero reflete as necessidades específicas de um grupo de interlocutores. Para Adair Bonini (2011), o gênero textual "poderia ser definido como a forma de agir e de se enunciar pela linguagem”. Podemos observar assim que tais acepçôes têm origem no conceito de gênero proposto por Mikhail Bakhtin (2003), para o qual os gêneros são "tipo relativamente estáveis de enunciados" ${ }^{3}$

\footnotetext{
${ }^{3}$ Neste trabalho, optou-se pelo uso mais constante do termo gênero textual em vez de gênero discursivo, proposto nos trabalhos de Mikhail Bakhtin. Tal escolha se deve ao fato de a expressão gênero textual não estar vinculada necessariamente a apenas uma corrente teórica. Visto que o trabalho é multidisciplinar e visa referir diversos teóricos, o termo mais amplo foi selecionado.
} 
Ainda de acordo com Bakhtin,

a riqueza e a diversidade dos gêneros do discurso são infinitas porque são inesgotáveis as possibilidades da multiforme atividade humana e porque em cada campo dessa atividade é integral o repertório de gêneros do discurso. (BAKHTIN, 2003, p. 262).

Dessa maneira, em contextos escolares é essencial propor aos alunos o envolvimento com gêneros textuais, a fim de intensificar o processo de trabalho com um texto socialmente significativo. Como a linguagem adequada aos mais diversos gêneros pode ser contextualizada e trabalhada em sala de aula, é interessante incluir, no currículo, planos baseados nos estudos de gêneros, de maneira autêntica, e não apenas tipificações textuais que não tenham valor significativo e coerente com a realidade do aluno. Conforme Bakhtin (2003) há uma bifurcação entre os gêneros secundários, aqueles mais complexos, criados em situações de convivência cultural, tais como os romances e pesquisas científicas, e os gêneros primários. Esses últimos, por sua vez, envolvem aqueles gêneros compostos de situações discursivas imediatas, tais como o diálogo cotidiano. De fato, na escola, mesmo os gêneros primários podem ser trabalhados, pois "até mesmo no bate-papo mais descontraído e livre nós moldamos o nosso discurso por determinadas formas de gênero" (BAKHTIN, 2003, p. 282). Ademais, podemos incluir também os gêneros derivados das novas tecnologias de informação e comunicação (TICs) - os gêneros digitais - que há pouco não existiam.

Desse modo, então, é interessante pensar em como as tecnologias podem influenciar as noçóes de gênero e contexto, provocando modificaçóes no uso e adequação da linguagem, com vistas a incorporar a discussão de tais questôes no contexto escolar.

Segundo Koch:

na concepção interacional (dialógica) da língua, na qual os sujeitos são vistos como atores/construtores sociais, o texto passa a ser considerado o próprio lugar da interação e os interlocutores, como sujeitos ativos que - dialogicamente - nele se constroem e são construídos. $(\mathrm{KOCH}$, 2002, p. 17).

Dessa maneira, é interessante trabalhar com aprendizes-autores e também professores-autores, aliados juntos em sala de aula, usando a citação acima como elemento disparador de discussões sobre a produção textual. Conforme Carlos A. Faraco (2005, p. 56), "se autorar é assumir uma posição 
axiológica, é deslocar-se para outra(s) voz(es) social(is)", de modo a construir gêneros que se adaptam às especificidades das tecnologias correntes.

De acordo com Pinheiro (2010, p. 34), "se os sistemas comunicativos estão passando por uma grande transformação, o estudo dos gêneros deve ser pensado dentro de uma (transform) ação que os reconsidere no mundo de seus usuários." Por conseguinte, nota-se que os gêneros se constituem historicamente e repercutem as redes sociais dos interlocutores. Consequentemente, nada mais natural que incluir o trabalho com a evolução desses gêneros também em sala de aula, de modo a "conceber o gênero, embora com uma certa estabilidade, não como um atributo fixo, mas como um instrumento passível de mudanças" (PINHEIRO, 2010, p. 50).

No presente trabalho, consideramos a fanfiction um gênero textual e não um gênero digital devido ao fato de que tal texto não necessita de um suporte eletrônico específico para ser desenvolvido. Contudo, apesar de ter origem na linguagem escrita, esse é um gênero característico da web, o qual, neste trabalho, é elaborado a partir da mineração textual.

\section{Recurso de mineração textual}

Ronen Feldman e Jim Sanger (2006) definem mineração de texto como um processo computacional no qual se busca analisar um ou mais documentos na busca de informaçōes relevantes, como, por exemplo, conceitos recorrentes, relacionamentos entre conceitos, dentre outros.

A ferramenta de mineração utilizada nesta pesquisa é o software livre Sobek, ${ }^{4}$ capaz de extrair termos recorrentes de um determinado texto e representá-los na forma de um grafo. Quanto a suas características técnicas, esse minerador de texto é um executável Java. Assim, após a instalação dessa ferramenta, é preciso apenas executar o arquivo referente ao minerador Sobek. Desse modo, a máquina que comporta a ferramenta precisa ter o programa Java. ${ }^{5}$

Acredita-se que tal representação gráfica pode ajudar os alunos a focar características específicas do texto e criar narrativas em LE. Para verificar essa hipótese, foi realizada uma investigação para avaliar como os alunos de LE lidam com o processo de criação de narrativas fanfiction usando a ferramenta de mineração.

${ }^{4}$ O minerador Sobek está disponível em <http://sobek.ufrgs.br>.
${ }^{5}$ Software Java. Download disponível em $<$ http://www.java.com/pt_BR>. 
Em relação a seu procedimento, Sobek é uma ferramenta capaz de extrair termos relevantes em documentos e encontrar os relacionamentos entre esses a partir de um processo conhecido como mineração de texto. Assim, o minerador écapaz de identificar conceitos ${ }^{6}$ importantes a partir da análise da frequência dos termos de um texto. Nesse procedimento, há a extração de conceitos e sua posterior visualização em um grafo, o qual éa representação gráfica que exibe elos entre os diferentes termos, estabelecendo suas relaçôes. Nesta pesquisa, o grafo é considerado um hipertexto passível de assistir o aluno em um processo no qual a imagem atua nessa facilitação, juntamente com as palavras.

Resumidamente, a ferramenta opera da seguinte maneira:

1. Copia-se o texto com o qual se quer trabalhar para a área de entrada de dados da ferramenta (tela inicial da ferramenta Sobek, aba "Text"). Alternativamente, carrega-se um texto em formato TXT, DOC ou PDF.

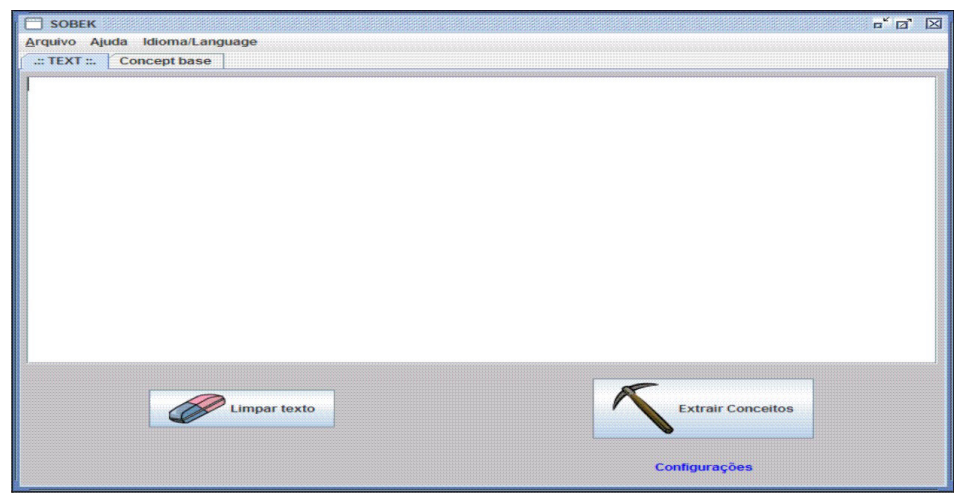

FIGURA 1 - Tela inicial da ferramenta Sobek

Fonte: Arquivo nosso.

2. A partir desse texto, uma base de conceitos é automaticamente criada através do processo de mineração de textos. Esses conceitos correspondem a um conjunto de termos que ocorrem com mais frequência no texto, excluindose artigos, preposiçôes e outras palavras consideradas sem significado relevante.

\footnotetext{
${ }^{6}$ Para fins de mineração textual, as expressōes termo e conceito são utilizadas de modo intercambiável.
} 


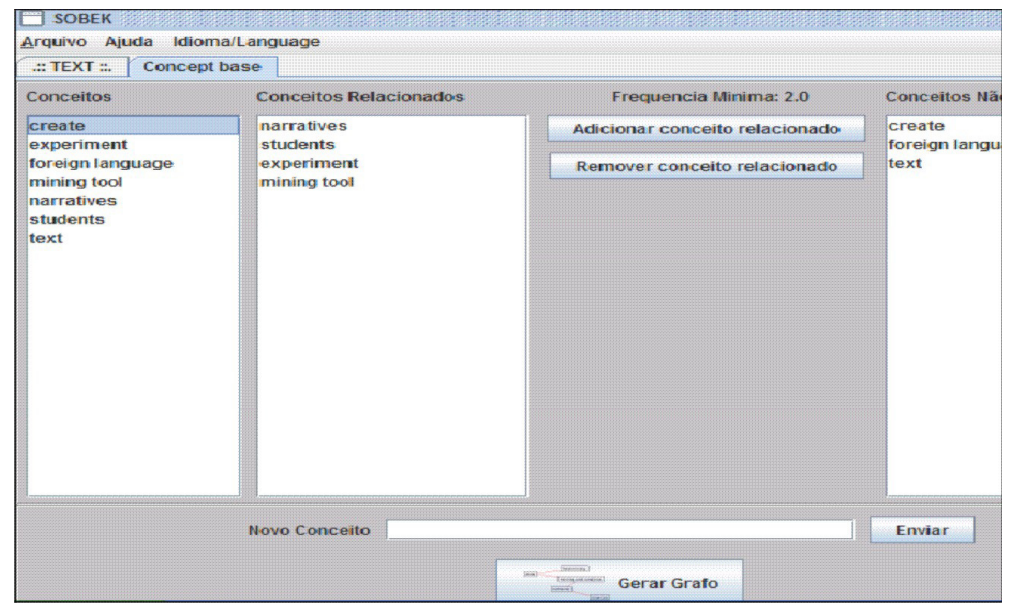

FIGURA 2 - Aba "Concept base" da ferramenta Sobek Fonte: Arquivo nosso.

3. Extraídos os conceitos, gera-se um grafo com os termos mais frequentes e seus relacionamentos. A figura abaixo mostra um exemplo de grafo extraído para uma fanfiction baseada no filme Avatar. ${ }^{7}$

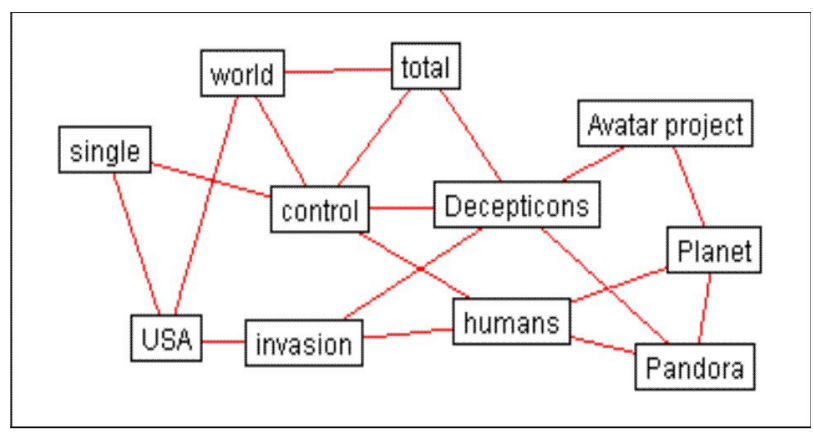

FIGURA 3 - Grafo baseado em uma fanfiction sobre o filme Avatar Fonte: Arquivo nosso.

A partir do exemplo, percebe-se que os termos extraídos estão efetivamente relacionados ao tema central do texto e do filme. É possível, inclusive, inferir possíveis frases a partir dos relacionamentos entre dois ou mais

${ }^{7}$ Grafo baseado em excertos iniciais do texto "Into the Fire", disponível em <http:/ /www.fanfiction.net/s/5844628/1/In_To_The_Fire>. 
nodos do grafo. A ideia, no entanto, não é reproduzir o texto original a partir dos grafos, mas sim instigar os estudantes a refletir sobre um tema, sobre um texto ou sobre suas próprias produçōes textuais.

\section{O estudo proposto}

Esta pesquisa é de natureza qualitativa, de cunho interpretativista, visto que são observadas as oportunidades de desenvolvimento de LE a partir de uma tarefa focada em mineração e letramento em meio eletrônico. Segundo Pinheiro (2011, p. 48), na pesquisa interpretativista "o conhecimento é reconhecido como algo construído na interpretação da linguagem, num processo de interação entre investigador e investigado, e, por isso, sempre aberto a novas interpretaçōes" (PINHEIRO, 2011, p. 48). Desse modo, nessa vertente de pesquisa, há um delineamento das percepçôes dos processos, por parte do pesquisador, juntamente com as percepçôes dos pesquisados. Assim, conforme aponta Luiz Paulo da Moita Lopes (1994), a pesquisa interpretativista é uma construção social, não somente focalizada em uma objetividade por parte do pesquisador.

No trabalho aqui proposto, os participantes da pesquisa são alunos em um curso de graduação em Letras de uma universidade federal do sul do país, com nível intermediário de inglês. Uma das pesquisadoras deste estudo atuava como professora substituta na turma e teve oportunidade de aplicar a tarefa durante sua prática docente. Quanto ao grupo de alunos, esse era composto de três duplas, formadas por seis alunos com faixa etária entre 19 e 24 anos e um estudante com 69 anos.

A aula prévia à geração de dados foi constituída por discussões sobre o gênero textual fanfiction e o uso prático da ferramenta de mineração de textos como forma de fomentar o processo de escrita. Durante essa aula foram discutidos dois textos de Black $(2005 ; 2009)$ e relatadas as experiências dos aprendizes sobre o tópico. Também houve conversas sobre diferentes tipos de fanfictions, de modo que os alunos tivessem algumas opções para sua criação. Uma aluna relatou ser leitora assídua de fanfiction, dois alunos já tinham ouvido falar sobre o assunto e outros três não conheciam a prática. Todos os encontros ocorreram em contexto presencial, em um laboratório de informática da universidade, no qual havia um computador disponível para cada participante.

$\mathrm{Na}$ sequência da aula introdutória, os alunos começaram a usar o site Fanfiction.net, explorando suas seçôes, a fim de escolher um tópico e finalmente uma história a ser lida, de acordo com suas preferências. Após esse 
insumo inicial, as principais características da ferramenta de mineração foram apresentadas, para que os aprendizes pudessem compreender os procedimentos para a extração de conceitos e geração de grafos. Posteriormente, a ferramenta foi efetivamente usada e cada indivíduo teve a oportunidade de criar um grafo de sua narrativa escolhida, adicionando e deletando termos e/ou relaçôes, de acordo com a leitura realizada. A partir dessa edição, os conceitos frequentes do texto foram formatados em um grafo, já que os aprendizes puderam excluir ou adicionar conceitos relacionados a termos específicos, a partir da edição nos ícones "Adicionar conceito relacionado" ou "Remover conceito relacionado", presentes na ferramenta. Após essas edições, os conceitos relacionados ao texto formaram um grafo, que pôde ser acessado a partir do ícone "Gerar grafo". Na investigação, o aluno A, após ler a história selecionada e editar conceitos, salvava o grafo resultante e o enviava por $e$-mail para o colega B. Igualmente o colega $\mathrm{B}$ manipulava a ferramenta e também mandava seu grafo ao colega $\mathrm{A}$. Portanto, B deveria criar uma fanfiction baseada no grafo recebido por A, enquanto o seu colega fazia o mesmo.

O aluno A ficava responsável por ler, editar termos e gerar o grafo, passível de ser um meio auxiliador para B, que seria o autor de um novo texto. Desse modo, a etapa de leitura de um texto original A era conduzida por A. Enquanto isso, o aluno B realizava a mesma tarefa, trabalhando com um texto diferente e produzindo dele um grafo a ser repassado para o aprendiz A. Mais tarde, ambos os estudantes lidaram com grafos diferentes compostos a partir de seu colega. A seguir, por exemplo, há um grafo feito pela aluna Fátima ${ }^{8}$ a partir de sua leitura de uma fanfiction sobre o seriado Friends. 'Posteriormente, o aluno escrevia um novo texto com base na imagem do grafo.

\footnotetext{
${ }^{8}$ Por razões éticas de pesquisa, todos os nomes citados neste trabalho são fictícios. 9 O grafo foi baseado em "TOW The Central Park Receipt", fanfiction disponível em <http://www.fanfiction.net/s/6050627/1/TOW_The_Central_Perk_Receipt $>$.
} 


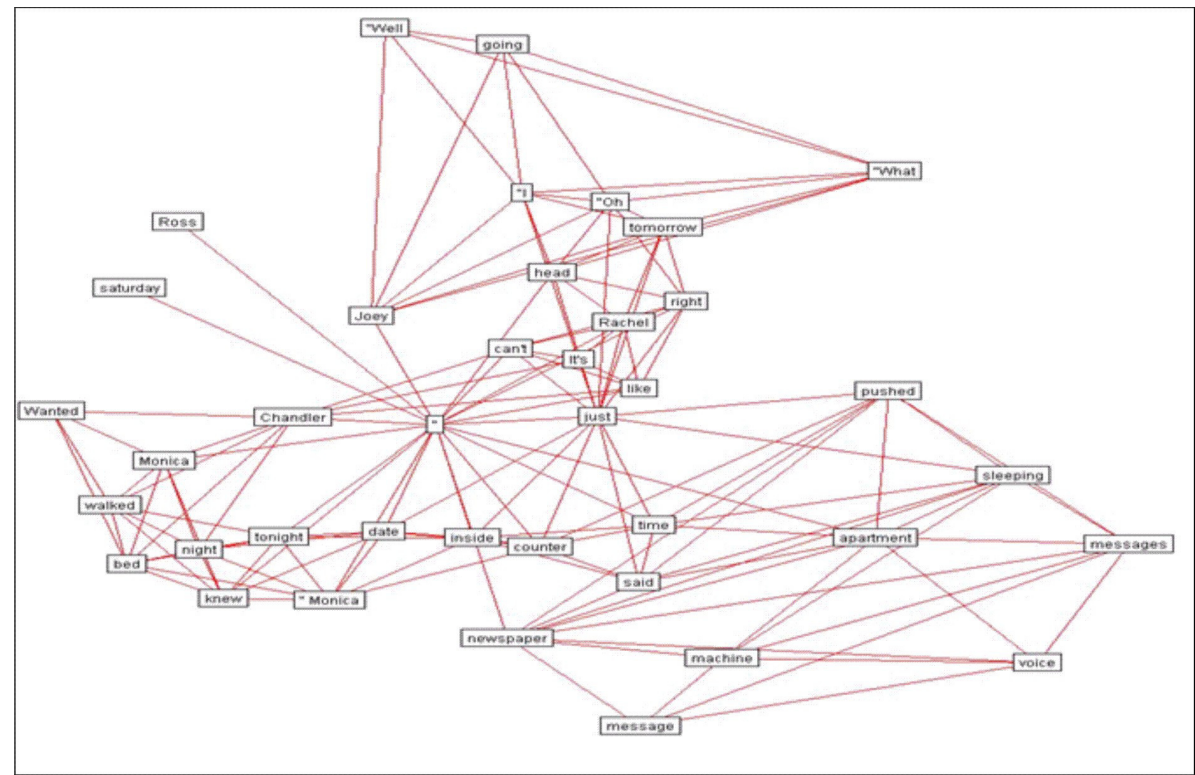

FIGURA 4 - Grafo criado na geração de dados, relativo a uma fanfiction sobre o seriado Friends

Fonte: Arquivo nosso.

Neste estudo, o procedimento escolhido foi a escrita individual, devido ao fato de a cultura de fanfiction na internet ter se iniciado com o texto escrito individualmente, que em um momento posterior era compartilhado com diversos leitores. Mesmo assim, o caráter da tarefa reflete colaboração, mesmo sem haver escrita coletiva, pois há um auxílio mútuo nas diversas etapas do trabalho. De acordo com Panitz (1996), a cooperação seria uma estrutura de interação projetada para facilitar o alcance a um objetivo. Desse modo, mesmo escrevendo individualmente, os aprendizes atuaram de modo a compor um trabalho colaborativo.

Cada aluno criou uma narrativa partindo do grafo como modelo inicial, utilizando para a escrita o editor de texto Word. Foi iniciado, então, o estudo para averiguar se esse processo de mineração poderia auxiliar o aprendiz com um recurso de rascunho de seu texto, por meio de um modelo de grafo que apoiasse a estruturação de sua narrativa. Adiante, teve início o processo de produção de textos por parte dos alunos, baseado na modelagem e na análise do grafo proveniente da fanfiction lida por seu colega. Posteriormente, o novo texto produzido pelo aluno e o texto original lido por seu colega foram comparados, a fim de se observarem as relações entre as narrativas e a presença de características que identificassem o 
gênero textual fanfiction. Finalmente, os textos escritos pelos alunos foram publicados no site Fanfiction.net, a fim de que seus colegas, assim como outros leitores, pudessem ser interlocutores dessas produçōes. Inicialmente, a ideia era fazer uma entrevista semiestruturada com os alunos, mas devido à aplicaçăo da tarefa ser em horário de aula, não puderam ser marcados encontros individuais com cada um. Então, ao final da investigação, os aprendizes receberam um questionário, a ser respondido em português (para que os alunos não ficassem reticentes em relação ao uso da LE), que foi preenchido por todos ao mesmo tempo. A partir de tais questionamentos houve, assim, o cuidado de fornecer uma visão êmica da pesquisa, diferente da visão externa (JOHNSON, 1992). Nessa perspectiva, há um cuidado com o ponto de vista do participante, que não está apenas sujeito às interpretaçōes do observador externo (pesquisador). Assim, no questionário havia as seguintes questōes:

1. O que você acha que foi positivo e/ou negativo na tarefa que você realizou?

2. Como você lidou com a ferramenta de mineração de texto (Sobek)? Como foi essa experiência?

3. Ao utilizar a ferramenta Sobek, como você fez a relação entre os conceitos? Que lógica você utilizou?

4. De que modo você acredita que tal ferramenta influencia a produção textual?

5. Como foi o processo de escrever uma fanfiction?

6. Como foi a experiência de escrever um texto baseado em um grafo?

7. Você tem outros comentários?

A partir de uma análise descritiva e interpretativista do processo de geração de dados, assim como através dos questionários, foram examinados indícios que indicam como a proposta da tarefa com a ferramenta digital influencia na produção. Através de um processo de triangulação dos dados a pesquisa foi conduzida. No entanto, por restrições de espaço, neste artigo é apresentada apenas uma parte dos dados analisados.

\section{Análise dos dados}

Todas as açôes dos alunos foram gravadas a partir de uma ferramenta de captura de tela, Debut Video Capture Software, ${ }^{10}$ através da qual os

${ }^{10} \mathrm{O}$ download do programa Debut Video Capture Software pode ser realizado em $<$ http://www.nchsoftware.com/capture/index.html>. 
movimentos do usuário na tela são registrados em vídeo. Foram registradas por volta de três horas e meia de ação de cada aluno, totalizando aproximadamente vinte horas de gravação. No presente artigo, alguns dos dados são apresentados a fim de exemplificação.

A tarefa proposta aos alunos pode ser classificada como estruturada, apresentando os passos específicos para o desenvolvimento da leitura e da escrita. Desse modo, a tarefa de escrever parece ganhar apoio, com base em um processo colaborativo $^{11}$ de trabalho. Segundo Idoia Elola (2010, p. 65), o trabalho colaborativo não deve substituir o trabalho individual, mas "ambas as abordagens podem se complementar e ampliar as experiências linguísticas dos escritores de uma maneira holística". Assim, o processo de criação se torna coletivo, pois dois aprendizes trabalham em diferentes estágios durante o desenvolvimento do texto.

Logo, para a análise desse trabalho, parte-se do questionamento sobre como a ferramenta Sobek pode auxiliar na produção textual de fanfictions e decorrente letramento em LE. Na observação dos dados, então, foram focalizados os seguintes índices:

a) A frequência com que o aprendiz retornava ao texto original, de modo a editar os termos antes da geração do grafo;

b) A frequência com que o aprendiz examinava o grafo enquanto escrevia um novo texto;

c) A recorrência dos termos presentes no grafo na nova produção do aprendiz;

d) A presença de tópicos, no novo texto do aprendiz, relacionados aos conceitos incluídos no grafo.

Para o presente artigo, são apresentados somente alguns dados referentes aos índices representados acima pelas letras (a) e (b), relacionados às ações dos aprendizes quando da realização da tarefa. Os dados referentes à produção textual serão relatados com mais profundidade em um estudo futuro. Além disso, focamos neste texto o trabalho conduzido pela aluna Fátima. Dessa forma, para um estudo maior, a observação dos índices acima e os depoimentos dos alunos consolidam o procedimento de triangulação de dados.

A seguir, segue uma tabela com a descrição de algumas ações tomadas por Fátima ao editar a aba de conceitos do Sobek, antes de produzir o grafo destinado à aluna Laís. A tabela abaixo indica a movimentação sequencial da

\footnotetext{
${ }_{11}$ No presente estudo, os termos colaboração e cooperação são utilizados de modo intercambiável.
} 
aluna ao utilizar o computador, visto que os números (explicitados na coluna à esquerda) indicam o tempo em que Fátima permanecia realizando a ação descrita na coluna à direita, de acordo com os movimentos registrados em tela.

\section{QUADRO 1}

Parte das ações tomadas pela aluna Fátima ao criar o grafo

\begin{tabular}{|c|c|}
\hline Tempo - filmagem $2^{12}$ & Açôes do aprendiz \\
\hline $15: 27-15: 35$ & $\begin{array}{l}\text { Fátima escolhe a fanfiction "Jumping to Conclusions", }{ }^{13} \text { do site } \\
\text { Fanfiction.net. }\end{array}$ \\
\hline $15: 36-18: 04$ & $\begin{array}{l}\text { Fátima seleciona e copia a história, antes de colá-la na página } \\
\text { inicial do Sobek. }\end{array}$ \\
\hline $18: 05-18: 15$ & $\begin{array}{l}\text { Fátima clica na opção "Extrair conceitos" da ferramenta e analisa } \\
\text { as relaçōes que foram estabelecidas automaticamente pelo } \\
\text { recurso de mineração. }\end{array}$ \\
\hline $18: 16-20: 00$ & $\begin{array}{l}\text { Fátima edita a aba "Conceitos", criando novas relaçôes entre } \\
\text { termos e removendo alguns conceitos. }\end{array}$ \\
\hline $20: 01-20: 38$ & Fátima clica em "Gerar grafo" e observa a imagem. \\
\hline $20: 39-21: 12$ & $\begin{array}{l}\text { Fátima retorna à "Base de conceitos" (“Concept base”) do } \\
\text { Sobek e edita mais termos. }\end{array}$ \\
\hline $21: 13-21: 39$ & Fátima clica em “Gerar grafo" e observa a imagem. \\
\hline $21: 40-23: 57$ & $\begin{array}{l}\text { Fátima retorna ao texto original, no site Fanfiction.net, e parece } \\
\text { ler o material novamente com mais atenção. }\end{array}$ \\
\hline
\end{tabular}

Fonte: Elaboração nossa.

A aprendiz parece analisar a sua compreensão de leitura, conforme ela vai e volta no texto, alternando sua leitura com a construção do grafo. Ela lê novamente o texto original, comparando os conceitos apresentados no grafo às relações semânticas estabelecidas em rede entre os termos da história. Portanto, ela retorna ao texto e pratica uma leitura mais atenta, de modo a estabelecer relações coerentes entre os termos destacados pelo software de mineração. Após a utilização do minerador, a gravação da tela indica que a leitura parece ser mais atenta, visto que a aluna acompanha a página, usando a barra de rolamento, levando um tempo maior para ler a história. Além da evidência do programa de gravação, esses momentos de leitura puderam ser confirmados devido à presença da pesquisadora

\footnotetext{
${ }^{12}$ Por razōes técnicas, o vídeo referente às ações dessa aluna foi dividido em duas partes. Portanto, a filmagem 2 do vídeo inicia aos $15 \min 27 \mathrm{~s}$.

${ }^{13}$ http://www.fanfiction.net/s/5958915/1/Jumping_to_Conclusions
} 
em sala de aula, no momento da geração de dados. Ademais, no questionário respondido pela aluna há o seguinte depoimento: "A experiência foi engraçada, pois no grafo às vezes tinha palavras que estavam ligadas a outras de forma estranha, então era preciso removê-las. Tinha, então, que voltar para o texto original e ler novamente pra fazer novas conexōes".

Há, portanto, uma tentativa de compreensão mais profunda do texto, de maneira que os conceitos do grafo estejam interligados e sejam significativos no momento de edição dos termos. Quando confrontado com o grafo do Sobek, o aprendiz precisa formular interpretaçôes sobre essa imagem, de modo a aproximá-la da representação mental que foi criada sobre um determinado tópico, a partir da história lida. Esse processo pode, então, levar a momentos de reflexão, embasando a prática de leitura do aluno, que depois também auxiliará na produção escrita.

Conforme se pode observar abaixo, há um processo de leitura mais atenta depois que a ferramenta é usada e o grafo é construído, já que o aprendiz pode retornar ao texto original, caso decida reler a história.

\section{QUADRO 2}

Continuação das ações tomadas pela aluna Fátima ao criar o grafo

\begin{tabular}{|c|c|}
\hline $\begin{array}{l}\text { Tempo-continuação } \\
\text { da filmagem } 2\end{array}$ & Açōes do aprendiz \\
\hline $23: 58-24: 04$ & $\begin{array}{l}\text { Novamente, Fátima consulta a seção sobre o seriado Friends, no } \\
\text { site Fanfiction.net, e procura por uma nova narrativa sobre o } \\
\text { mesmo tema. }\end{array}$ \\
\hline $24: 05-24: 10$ & Fátima escolhe a fanfiction "TOW The Central Park receipt". ${ }^{14}$ \\
\hline $24: 11-24: 31$ & $\begin{array}{l}\text { Fátima seleciona e copia a nova história, antes de colá-la na página } \\
\text { inicial do Sobek. }\end{array}$ \\
\hline $24: 32-24: 39$ & $\begin{array}{l}\text { Fátima clica em "Extrair conceitos" e analisa as relaçôes que foram } \\
\text { estabelecidas através do minerador. }\end{array}$ \\
\hline $24: 40-32: 56$ & Fátima retorna ao texto original e começa a lê-lo com mais atenção. \\
\hline $32: 57-33: 00$ & Fátima retorna ao Sobek e gera um grafo do texto lido. \\
\hline $33: 01-35: 33$ & Fátima retorna à "Base de conceitos" do Sobek e edita mais termos. \\
\hline $35: 34-37: 23$ & $\begin{array}{l}\text { Fátima gera um novo grafo e o salva como versão final. Tal imagem } \\
\text { representa a FIG. 4, exposta na seção anterior deste trabalho. }\end{array}$ \\
\hline
\end{tabular}

Fonte: Elaboração nossa.

${ }^{14} \mathrm{http}: / /$ www.fanfiction.net/s/6050627/1/TOW_The_Central_Perk_Receipt 
Observa-se que os conceitos foram editados mais de uma vez e depois incorporados a um novo gráfico. Logo, parece que a finalidade da aprendiz era de fornecer um grafo coerente e oganizado para seu par, de modo que sua colega tivesse uma ilustração compreensível para apoiar a escrita. Ademais, os termos que estavam presentes no grafo, foram recorrentemente utilizados por Fátima e por Laís em seus novos textos. Assim, os alunos não tiveram de enfrentar uma página em branco - uma restrição com a qual muitos escritores têm de lidar e que pode se transformar em um real pânico do papel em branco, segundo Ann Raimes (1998). Tais indícios observados durante a geração de dados apontam que a ferramenta também serviu para dar um prompt inicial, deflagrando uma possibilidade de processo mais fluido da escrita.

Conforme alguns depoimentos, coletados a partir do questionário, podese observar como foi a percepção dos aprendizes em relação a essa experiência.

Fátima: Foi uma experiência diferente e interessante, pois tive que tentar ao máximo manter a relação que o grafo mostrava, ao mesmo tempo em que exercitava minha criatividade na construção da narrativa.

Lais: Eu achei interessante ter que criar uma nova história a partir de um gráfico, pois nele estava as informações que o outro colega tinha coletado. O mais interessante é poder escrever a partir das nossas perspectivas perante palavras aleatórias, o que pode sair dali de palavras genéricas.

Otávio: Instigante trabalhar com termos destacados por outro colega, do texto lido por ele e conteúdos por mim desconhecidos e com eles elaborar a minha narrativa.

André: Foi bom, pois como eu era familiar com os termos e personagens da fanfiction acabei utilizando do meu background pra fazer as ligações, além de ler o texto.

Inês: Foi boa (a experiência), acredito que bastante positiva pois o grafo funcionou como um facilitador na escrita do texto, delimitando o tema e propondo conexôes entre os elementos da fanfiction.

Vicente: A ferramenta é interessante como forma de selecionar as palavras-chave do texto, e também, através da tarefa executada, de instigar a produção textual criativa.

A partir da análise dessa tarefa, foi possível observar que os gráficos gerados pela ferramenta desempenharam um papel importante no processo de análise das fanfictions e produção de textos. Oralmente, durante a realização da 
tarefa, os alunos também fizeram comentários a respeito de como o exame dos grafos os fez ficar retornando aos textos originais, ao mesmo tempo em que alternavam a volta à janela do grafo, a fim de melhor compreender os textos e criar uma imagem mais clara das histórias para seus colegas. O momento de escrita de fato, partindo da visão do grafo, pareceu ser uma maneira interessante de instigar os alunos a criar novas histórias baseadas em algumas ideias centrais representadas pela imagem.

Assim, a investigação propiciou a aplicação de uma abordagem focada na produção textual, mediada pela mineração. A partir da análise dessa tarefa, observou-se que os grafos gerados pela ferramenta de mineração de texto desempenharam um papel importante na análise das fanfictions e subsequente produção de textos, por parte dos aprendizes. Os dados fornecidos pelos participantes da pesquisa indicam que os grafos os ajudaram a refletir e criar uma imagem mais clara das histórias que estavam prestes a escrever. $\mathrm{O}$ grafo representaria, então, uma figura gráfica capaz de revelar uma representação concisa de um texto. A análise dessas imagens os fez ir e voltar aos textos originais, a fim de melhor compreendê-los e criar uma representação mais completa das histórias para seus pares. Além disso, a escrita de fanfictions baseada no grafo também demonstrou ser uma forma diferenciada de produção, apoiada em palavras-chave ou ideias centrais. Assim, a participação em um novo letramento a partir dessa produção específica é possível através de um processo mediado pela ferramenta, pela língua e pela interação entre os indivíduos.

\section{Considerações finais}

De acordo com Robert J. Sternberg (2006), a unidade fundamental do conhecimento simbólico é o conceito, que pode ser organizado em categorias e esquemas em nossa mente. $\mathrm{O}$ autor afirma que o leitor cria um modelo mental do texto que está sendo lido, o qual pode ser considerado uma espécie de modelo de funcionamento interno da situação descrita no texto, conforme entendida pelo leitor. Em outras palavras, o leitor cria uma representação mental que contém em si os principais elementos do texto. Ainda, segundo Sternberg (2006), a construção de modelos mentais ilustra que, além de entendê-los, também compreendemos como eles se combinam em representações integradas de significado, quando lemos uma história, por exemplo.

A partir dessa discussão, acreditamos que uma ferramenta de mineração de texto como o Sobek pode agir como um dispositivo conveniente para 
materializar esse modelo mental em um grafo visual que represente um texto por meio de conexôes entre os conceitos. Dessa maneira, a ferramenta pode promover o desenvolvimento de LE, uma vez que o aluno tem a oportunidade de trabalhar com o minerador, a fim de escrever textos autênticos, como o gênero textual fanfiction. Assim, o processo de produção de textos pode estar vinculado a um evento de letramento, o qual, nesse caso, consiste em escrita significativa a ser compartilhada na web.

Até o momento, a principal contribuição deste trabalho é a de oportunizar uma reflexão acerca das possibilidades de promoção de letramento em LE através de tarefas de criação de fanfictions, apoiadas por um recurso de mineração textual. Desse modo, discutimos de que modo o ambiente digital pode ser um vetor auxiliador da aprendizagem através de tarefas pedagogicamente significativas. Pensamos que tais propostas em ambiente digital podem fomentar a participação do aluno de modo ativo e autônomo na leitura e na produção, visto que os textos produzidos são autênticos gêneros textuais. Assim, o papel do aluno pode ser enfatizado em tais tarefas, pois os aprendizes terão suas produções compartilhadas entre interlocutores reais.

Desse modo, a mediação da tecnologia é apenas um fator no complexo processo de aprendizagem, o qual apresenta um cenário composto do professor, alunos e diversos outros aspectos que influenciam o contexto de sala de aula. A aprendizagem é um processo que não atinge um resultado final, visto que segue modificando as percepções do aprendiz, o qual faz novas conexões com conhecimentos adquiridos anteriormente, utilizando-se de interaçôes e ferramentas no seu desenvolvimento. No ensino mediado por computador, é essencial que o professor, além das ferramentas, também seja um aliado do aluno, de modo a construir tarefas passíveis de incentivar a autonomia do aprendiz. Tais açóes podem ser fomentadas a partir de tarefas disparadoras de reflexão e produção, desafiando o aluno que lida com as ferramentas tecnológicas a exercer suas práticas de letramento.

\section{Referências}

BAKHTIN, M. Os gêneros do discurso. In: . Estética da criação verbal. São Paulo: Martins Fontes, 2003. p. 270-306.

BARTON, D.; HAMILTON, M. Literacy Practices. In: .; IVANIC, R.

(Ed.). Situated Literacies: Reading and Writing in Context. New York: Routledge, 2000. p. 7-15. 
BLACK, R. W. Access and Affiliation: The Literacy and Composition Practices of English-Language Learners in an Online Fanfiction Community. Journal of Adolescent and Adult Literacy, v. 49, p. 118-128, Oct. 2005.

. Digital Design: English Language Learners and Reader Reviews in Online Fiction. In: KNOBEL, M.; LANKSHEAR, C. (Ed.). A New Literacies Sampler. New York: Peter Lang, 2007. p. 115-136.

. Online Fan Fiction, Global Identities, and Imagination. Research in the Teaching of English, v. 43, n. 4, p. 397-425, May 2009.

BONINI, Adair. Jornal escolar: gêneros e letramento midiático no ensinoaprendizagem de linguagem. Revista Brasileira de Linguística Aplicada, Belo Horizonte, v. 11, n. 1, p. 149-175, 2011. Disponível em: <http:// www.scielo.br/pdf/rbla/v11n1/v11n1a09.pdf>. Acesso em: 6 set. 2012.

BUZATO, M. Entre a fronteira e a periferia: linguagem e letramento na inclusão digital. 2007. 284 f. Tese (Doutorado em Linguística Aplicada) Instituto de Estudos da Linguagem, Universidade Estadual de Campinas, Campinas, 2007.

. O letramento eletrônico e o uso do computador no ensino de Lingua Estrangeira: contribuições para a formação de professores. $2001.188 \mathrm{f}$. Dissertação (Mestrado em Linguística Aplicada) - Instituto de Estudos da Linguagem, Universidade Estadual de Campinas, Campinas, 2001.

ELOLA, I. Collaborative Writing: Fostering Foreign Language and Writing Conventions Development. Language Learning \& Technology, v. 14, n. 3, p. 51 71, Oct. 2010. Disponível em: <http://llt.msu.edu/issues/october2010/ elolaoskoz.pdf>. Acesso em: 6 set. 2012.

FARACO, C. A. Autor e autoria. In: BRAIT, B. (Org.). Bakhtin: conceitoschave. São Paulo: Contexto, 2005. p. 37-60.

FELDMAN, R.; SANGER, J. Text Mining Handbook. Cambridge (MA): Cambridge University Press, 2006.

GEE, J. P. Social Linguistics and Literacies: Ideology in Discourses. London: Falmer, 1996.

GEE, J. P.; HULL, G.; LANKSHEAR, C. The New Work Order: Behind the Language of the New Capitalism. Boulder: Westview, 1996.

HULL, G.; SCHULTZ, K. Literacy and Learning Out of School: A Review of Theory and Research. Review of Educational Research, v. 71, n. 4, p. 575-611, Winter 2001.

JOHNSON, D. Approaches to Research in Second Language Learning. New York: Longman, 1992. 
KERN, R.; WARSCHAUER, M. Theory and Practice of Network-Based Language Teaching. In: WARSCHAUER, M.; KERN, R. (Ed.). Network-Based Language Teaching: Concepts and Practice. New York: Cambridge University Press, 2000. p. 1-19.

$\mathrm{KOCH}$, I. Concepções de língua, sujeito e sentido. In: KOCH, I. Desvendando os segredos do texto. São Paulo: Cortez, 2002. p. 13-20.

LANKSHEAR, C.; KNOBEL, M. New Literacies: Changing Knowledge and Classroom Learning. Buckingham: Open University Press, 2003.

. Sampling "The New" in New Literacies. In: KNOBEL, M.; LANKSHEAR, C. (Ed.). A New Literacies Sampler. New York: Peter Lang, 2007. p. 1-24.

LÉVY, P. A inteligência coletiva: por uma antropologia do ciberespaço. São Paulo: Loyola, 1998.

LIMA, M. dos S.; CAMPELO COSTA, P. da S. O diálogo colaborativo como ação potencial para a aprendizagem de línguas. Trabalhos em Linguistica Aplicada, Campinas, v. 49, n. 1, p. 167-184, jan.-jun. 2010. Disponível em: <http:// www.scielo.br/pdf/tla/v49n1/12.pdf>. Acesso em: 6 set. 2012.

MOITA LOPES, L. P. da. Pesquisa interpretativa em linguística aplicada: a linguagem como condição e solução. DELTA: Documentação de Estudos em Linguística Teórica e Aplicada, São Paulo, v. 10, n. 2, p. 329-338, 1994.

O'REILLY, T. What Is Web 2.0? Design Patterns and Business Models for the Next Generation of Software. 30 Sept. 2005. Disponível em: <www.oreillynet. $\mathrm{com} / \mathrm{pub} / \mathrm{a} /$ oreilly/tim/news/2005/09/30/what-is-web-20.html>. Acesso em: 4 jan. 2012.

PANITZ, T. A Definition of Collaborative vs Cooperative Learning. 1996. Disponível em: <http://www.londonmet.ac.uk/deliberations/collaborativelearning/panitz-paper.cfm> Acesso em: 12 nov. 2011.

PINHEIRO, P. A. Gêneros (digitais) em foco: por uma discussão sócio-histórica. Alfa, São José do Rio Preto, v. 54, n. 1, p. 33-58, 2010. Disponível em: <http:/ /seer.fclar.unesp.br/alfa/article/view/2870/2644>. Acesso em: 6 set. 2012.

. Práticas colaborativas de escrita por meio de ferramentas da internet: ressignificando a produção textual na escola. 2011. $247 \mathrm{f}$. Tese (Doutorado em Linguística Aplicada) - Instituto de Estudos da Linguagem, Universidade Estadual de Campinas, Campinas, 2011.

RAIMES, A. Exploring Through Writing: A Process Approach to ESL Composition, 1998.

SCRIBNER, S.; COLE, M. The Psychology of Literacy. Cambridge (MA): Harvard University Press, 1981. 
SOARES, M. Novas práticas de leitura e escrita: letramento na cibercultura. Educação \& Sociedade, Campinas, v. 23, n. 81, p. 143-160, dez. 2002. Disponível em: <http://www.scielo.br/pdf/es/v23n81/13935.pdf>. Acesso em: 6 set. 2012.

. Português: uma proposta para o letramento. São Paulo: Moderna, 1999. STERNBERG, R. Cognitive Psychology. Belmont (CA): Cengage, 2006.

STONE, J. Popular Websites in Adolescents' Out-of-School Lives: Critical Lessons on Literacy. In: LANKSHEAR, C.; KNOBEL, M. (Ed.). A New Literacies Sampler. New York: Peter Lang, 2007. p. 49-65.

STREET, B. V. Literacy and Development: Ethnographic Perspectives. London: Routledge, 2001. . Social Literacies. New York: Longman, 1995.

STREET, J. C.; STREET, B. V. The Schooling of Literacy. In: BARTON, D.; IVANIC, R. (Ed.). Writing in the Community. Newbury Park: Sage, 1991. p. 106-131.

SWALES, J. Genre Analysis: English in Academic and Research Settings. Cambridge (MA): Cambridge University Press, 1990.

TFOUNI, L. V. Letramento e alfabetização. São Paulo: Cortez, 1995.

VYGOTSKY, L. S. A formação social da mente: o desenvolvimento dos processos psicológicos superiores. São Paulo: Martins Fontes, 1998.

. Thought and Language. Cambridge (MA): MIT Press, 1986.

WARSCHAUER, M. Millennialism and Media: Language, Literacy, and Technology in the $21^{\text {st }}$ Century. AILA Review, v. 14, p. 49-59, 2001.

. Tecnologia e inclusão social: a exclusão digital em debate. São Paulo: Senac, 2006.

WIBLE, D.; KUO, C.; TSAO, N. Contextualizing Language Learning in the Digital Wild: Tools and a Framework. In: IEEE INTERNATIONAL CONFERENCE ON ADVANCED LEARNING TECHNOLOGIES (ICALT'04), 4., 2004, Jeonsuu. Proceedings... Washington: IEEE, 2004. p. 231-235.

Recebido em 01/03/2012. Aprovado em 28/08/2012. 